\title{
Detection of the parasitic dinoflagellate Hematodinium in the Norway lobster Nephrops norvegicus by ELISA
}

\author{
H. J. Small ${ }^{1, *}$, S. Wilson ${ }^{2}$, D. M. Neil ${ }^{1}$, P. Hagan $^{2}$, G. H. Coombs ${ }^{2}$ \\ ${ }^{1}$ Division of Environmental and Evolutionary Biology, Graham Kerr Building, and ${ }^{2}$ Division of Infection and Immunity, \\ Joseph Black Building, University of Glasgow, Glasgow G12 8QQ, Scotland, UK
}

\begin{abstract}
Norway lobsters Nephrops norvegicus from the coastal waters of Scotland are seasonally infected by a parasitic dinoflagellate of the genus Hematodinium. An enzymelinked immunosorbent assay (ELISA) has been developed for the detection of the parasite in the haemolymph of $N$. norvegicus. The ELISA is simple to perform with a detection limit of $5 \times 10^{4}$ parasites $\mathrm{ml}^{-1}$ haemolymph. The ELISA is currently being used to study the prevalence and seasonality of Hematodinium infection in $N$. norvegicus and other crustacean hosts
\end{abstract}

KEY WORDS: Hematodinium - Nephrops norvegicus . Infection · ELISA

Resale or republication not permitted without written consent of the publisher

The Norway lobster Nephrops norvegicus supports a major commercial fishery in the Northeast Atlantic. Lobster populations of this region harbour an infection by a parasitic dinoflagellate of the genus Hematodinium (Field et al. 1992). Infection of $N$. norvegicus by Hematodinium species was initially diagnosed by the dull orange colouration of the carapace and appendages; such lobsters were also observed to be moribund with milky white haemolymph. However, this diagnostic method lacks sensitivity as only advanced infections can be reliably identified (Field et al. 1992, Stentiford et al. 2001a). A more sensitive method was later developed in which the pleopod is examined under low power light microscopy for the aggregation of parasites in the vasculature (Field et al. 1992, Field \& Appleton 1995). The severity of infection is staged using a 5-point scale, from uninfected to the most advanced infection. The pleopod method is a reliable field method for identifying advanced infections, but it is unable to detect low level haemolymph infection,

*E-mail: 9909258s@student.gla.ac.uk and also requires a degree of training and standardisation.

Immunodiagnostic techniques can detect several pathogens of marine organisms (Bryant et al. 1999, Poulos et al. 1999, Hsu et al. 2000). An indirect fluorescent antibody technique (IFAT) developed using a polyclonal rabbit antiserum raised against an in vitro culture of several vegetative forms of Hematodinium from Nephrops norvegicus showed that some N. norvegicus harbour infections outside of the main infective season (Field \& Appleton 1996). More recently, a Western blot method has been developed using the polyclonal anti-Hematodinium antiserum and applied to study the occurrence and progression of infection (Stentiford et al. 2001b). Both immunoassays offer greater sensitivity and specificity than the previous diagnostic methods, but are time-consuming and complex procedures, requiring trained personnel. Hence an enzyme-linked immunosorbent assay (ELISA) has been developed which can screen large numbers of samples in a short time and has greater sensitivity than the Western blot procedure.

Materials and methods. Collection and maintenance of lobsters: Norway lobsters Nephrops norvegicus were caught by otter bottom trawl (70 mm mesh size) at locations south of Little Cumbrae in the Clyde Sea Area $\left(55.41^{\circ} \mathrm{N}, 4.56^{\circ} \mathrm{W}\right)$. The lobsters were transported in a cool, damp environment after capture, then maintained in a closed seawater system at $10^{\circ} \mathrm{C}$ and $33 \%$ salinity prior to experimental study.

Haemolymph preparation: For routine assessment, haemolymph samples were withdrawn from the base of the fifth pereiopod using a $1 \mathrm{ml}$ disposable syringe and 25-gauge needle, allowed to clot, frozen to $-20^{\circ} \mathrm{C}$ and thawed once. All subsequent treatments were performed at $22^{\circ} \mathrm{C}$. The haemolymph samples were vortexed and a $15 \mu$ l aliquot of each haemolymph sample 
was then diluted in $285 \mu \mathrm{l}$ of distilled water. From this, $100 \mu \mathrm{l}$ was transferred into each of 2 wells of a 96-well microtiter plate (Immulon $4 \mathrm{HBX}$ ); for each haemolymph sample the ELISA was carried out in duplicate. After initial incubation for $30 \mathrm{~min}$, plates were washed 4 times with phosphate-buffered saline (PBS) ( $\mathrm{pH}$ 7.2) with $0.05 \% \mathrm{v} / \mathrm{v}$ Tween 20 . Plates were then incubated for 30 min with $100 \mathrm{\mu l} \mathrm{well}^{-1}$ rabbit anti-Hematodinium antiserum (1/2000 dilution) (see Field \& Appleton 1996 for antiserum production). Plates were again washed 4 times, followed by a third incubation for 30 min with $100 \mu \mathrm{l} \mathrm{well}{ }^{-1}$ goat anti-rabbit horseradish peroxidase conjugated antibody (1/500 dilution) (Diagnostics Scotland). Plates were washed 4 times and $100 \mu \mathrm{l} \mathrm{TMB}$ substrate $\left(3,3^{\prime}, 5\right.$, 5'-tetramethyl benzidine) (Dynex Technologies) applied for colour development by incubation for 20 min in darkness. The optical density (OD) of the wells in the microtiter plate was then measured at $690 \mathrm{~nm}$ with an ELISA reader (Titertec Multiscan).

Sensitivity of ELISA: For determining the sensitivity of the ELISA test, a haemolymph sample was taken from a lobster that gave a positive result in the routine ELISA assessment, but displayed no external signs of infection. An aliquot of this sample was diluted 1:1 in marine anticoagulant ( $450 \mathrm{mM}$ sodium chloride, $100 \mathrm{mM}$ glucose, $30 \mathrm{mM}$ trisodium citrate, $26 \mathrm{mM}$ citric acid and $10 \mathrm{mM}$

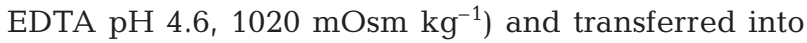
an Improved Neubauer counting chamber. Parasite cell numbers were counted and the numbers per ml estimated using standard procedures. The sample was frozen to $-20^{\circ} \mathrm{C}$, then thawed and 6 aliquots were serially 2 -fold diluted and assayed by the ELISA procedure above. A sample of uninfected haemolymph was assayed by the same method and a comparison of the OD values from infected and uninfected haemolymph was performed by the Mann-Whitney $U$-test. Significance was considered to be at $\mathrm{p}<0.005$.

Comparison of techniques for detection: Routine assessment of infection was made on a sub-sample from 2 monthly trawls using both the pleopod staging method of Field \& Appleton (1995), and Western blotting of haemolymph samples described by Stentiford et al. (2001b). These assessments were then compared with the results from the ELISA conducted on the same haemolymph samples. Haemolymph samples from lobsters testing positive for Hematodinium infection by the ELISA method alone were assayed by the IFAT technique of Field \& Appleton (1996) to confirm infection status. In this instance, the bovine serum albumin (BSA) used during the washing steps was replaced by an equivalent amount of porcine gelatin, because the anti-Hematodinium antibody reacts with BSA on Western blots (Stentiford et al. 2001b).

Results. Evaluation and sensitivity of ELISA: The ELISA could detect the presence of Hematodinium in

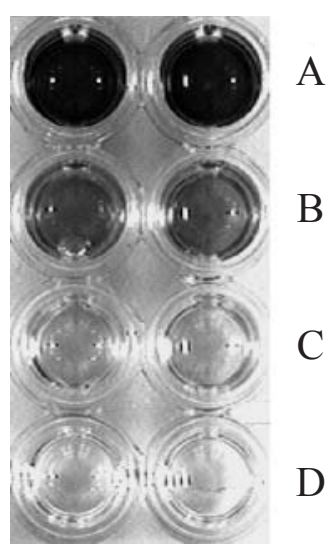

Fig. 1. Section of ELISA plate showing (A) advanced infection, (B) low-level infection, (C) uninfected, and (D) negative control ELISA reactions

haemolymph samples. There was some antibody binding in uninfected samples but this was considerably lower than for both low-level and advanced infection samples (Fig. 1).

Serial dilutions of a haemolymph sample with a known number of parasites present were used to determine the sensitivity of the assay (Fig. 2). The lowest density sample that was significantly different from the uninfected haemolymph sample was taken to represent the limit of detection of the assay $\left(5 \times 10^{4}\right.$ parasites $\mathrm{ml}^{-1}$ haemolymph).

Comparison of diagnostic methods: The diagnosis of Hematodinium species infection in 2 monthly subsets of 30 lobsters taken at times before the seasonal peak of infection, assessed by the pleopod, Western blot and ELISA methods, is shown in Table 1. By the pleopod method, all lobsters were assessed to be uninfected but by the antibody based methods a number of individuals were found to be infected. All haemolymph infections identified by Western blotting were also found to be positive by ELISA, but conversely not all infections identified by ELISA were detected by Western blotting. Comparison of the ELISA and IFAT results on these samples however, gave the same positive infection diagnosis (data not shown).

Discussion. The results obtained show that the ELISA is a sensitive and specific diagnostic test for the presence of Hematodinium parasites in the haemolymph of the Norway lobster. In common with the

Table 1. Comparison of Hematodinium infection diagnosis in a sub-sample of 30 lobsters by pleopod assessment, haemolymph Western blot, and haemolymph ELISA

\begin{tabular}{|lccc|}
\hline $\begin{array}{l}\text { Date } \\
(\mathrm{d} / \mathrm{mo} / \mathrm{yr})\end{array}$ & $\begin{array}{c}\text { Pleopod } \\
\text { (prevalence) }\end{array}$ & $\begin{array}{c}\text { Western blot } \\
\text { (prevalence) }\end{array}$ & $\begin{array}{c}\text { ELISA } \\
\text { (prevalence) }\end{array}$ \\
\hline 10/10/00 & $0 / 30$ & $4 / 30$ & $8 / 30$ \\
$06 / 11 / 00$ & $0 / 30$ & $5 / 30$ & $6 / 30$ \\
\hline
\end{tabular}




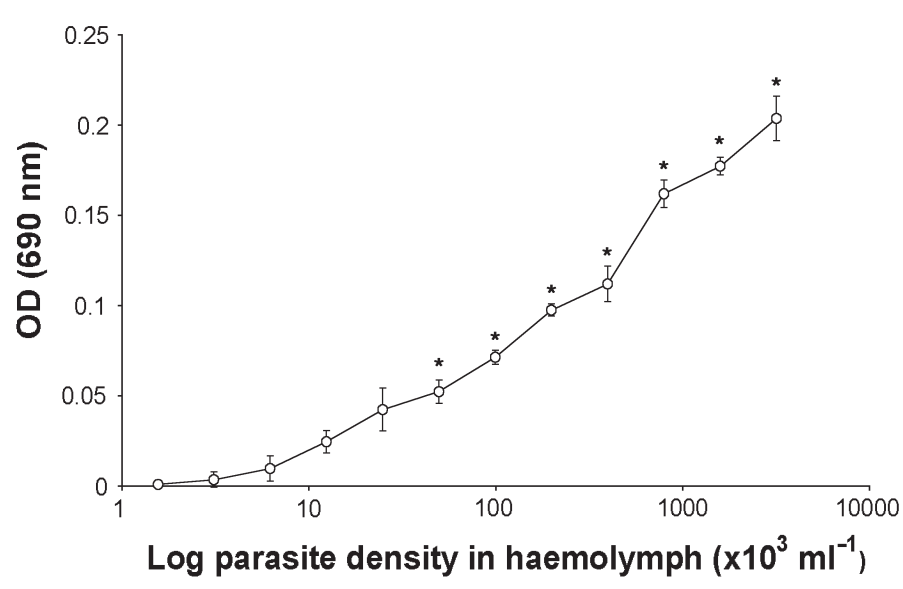

Fig. 2. Sensitivity of ELISA for Hematodinium. Infected haemolymph from an infected Norway lobster was serially 2-fold diluted and assayed by the ELISA. Uninfected haemolymph assayed by the ELISA had a mean optical density (OD) value of 0.037 with a standard deviation (SD) of 0.008 . Data points represent means $\pm \mathrm{SD}(\mathrm{n}=6)$. ${ }^{*} \mathrm{p}<0.005$ between uninfected and infected haemolymph

Western blot method of Stentiford et al. (2001b), it can detect both low-level and advanced infections. Moreover, it offers significant advantages over the Western blot procedure in terms of its sensitivity, simplicity and the number of samples that can be assayed. Importantly for routine use, the difference between positive and negative samples was visible by eye.

The sensitivity of the ELISA has been determined to be $5 \times 10^{4}$ parasites $\mathrm{ml}^{-1}$ haemolymph, making it more sensitive than the Western blot procedure by a factor of 4 . This is consistent with the observation that several low-level infections identified by the ELISA were not detected by the Western blot.

The ability of the ELISA to test multiple samples within a short period, without sophisticated analytical equipment is a significant development. Previous immunological methods such as the IFAT and Western blot are complex and time-consuming. The ELISA requires only a small volume of haemolymph to conduct the test; host lobsters need not be damaged, and if necessary the sampled individuals can be kept alive for further observation under laboratory conditions.

The ELISA will be particularly useful in the identification of Hematodinium sp. infections in previously unexamined Nephrops norvegicus stocks. In addition, the ELISA could be used to identify Hematodinium infections in other crustacean species, since Stentiford et al. (2002) have shown that the primary anti-Hematodinium antibody is also reactive to a Hematodinium-like parasite of the European edible crab Cancer pagurus.
The finding by Bushek at al. (2002) that the polyclonal anti-Hematodinium antiserum used in this study is reactive against shared antibody binding epitopes on cells of the oyster pathogen Perkinsus marinus raises interesting issues concerning the affinity of Hematodinium and Perkinsus. However, this does not affect the usefulness of the antiserum in detecting Hematodinium in crustaceans as $P$. marinus is exclusively a mollusc pathogen.

Acknowledgements. Support for this research was provided by a contract from the Ministry of Agriculture Fisheries and Food, United Kingdom (Contract No. CSA 4172, project code MFO221) and a Natural Environment Research Council Studentship (NER/S/A/2000/03368) to H.J.S. The authors thank the crew of the RV 'Aora' (University Marine Biological Station, Millport) for assistance in collection of lobster.

\section{LITERATURE CITED}

Bryant MS, Lee RP, Lester RJG, Whittington RJ (1999) Antiimmunoglobulin antisera used in an ELISA to detect antibodies in barramundi Lates calcarifer to Cryptocaryon irritans. Dis Aquat Org 36:21-28

Bushek D, Dungan CF, Lewitus AJ (2002) Serological affinities of the oyster pathogen Perkinsus marinus (Apicomplexa) with some dinoflagellates (Dinophyceae). Eukaryot Microbiol 49:11-16

Field RH, Appleton PL (1995) A Hematodinium-like dinoflagellate infection of the Norway lobster Nephrops norvegicus: observations on pathology and progression of infection. Dis Aquat Org 22:115-128

Field RH, Appleton PL (1996) An indirect fluorescent antibody technique for the diagnosis of Hematodinium sp. infection of the Norway lobster Nephrops norvegicus. Dis Aquat Org 24:199-204

Field RH, Chapman CJ, Taylor AC, Neil DM, Vickerman K (1992) Infection of the Norway lobster Nephrops norvegicus by a Hematodinium-like species of dinoflagellate on the west coast of Scotland. Dis Aquat Org 13:1-15

Hsu YL, Wang KH, Yang YH, Tung MC, Hu CH, Lo CF, Wang $\mathrm{CH}$, Hsu T (2000) Diagnosis of Penaeus monodon-type baculovirus by PCR and by ELISA of occlusion bodies. Dis Aquat Org 40:93-99

Poulos BT, Kibler R, Bradley-Dunlop D, Mohney LL, Lightner DV (1999). Production and use of antibodies for the detection of Taura syndrome virus in penaeid shrimp. Dis Aquat Org 37:99-106

Stentiford GD, Neil DM, Atkinson RJA (2001a) The relationship of Hematodinium infection prevalence in a Scottish Nephrops norvegicus population to seasonality, moulting and sex. ICES J Mar Sci 58:814-823

Stentiford GD, Neil DM, Coombs GH (2001b) Development and application of an immunoassay diagnostic technique for studying Hematodinium infections in Nephrops norvegicus populations. Dis Aquat Org 46:223-229

Stentiford GD, Green M, Bateman K, Small HJ, Neil DM, Feist SW (2002) Pink Crab Disease (PCD) of the edible crab Cancer pagurus is caused by an infection by a Hematodiniumlike parasitic dinoflagellate. J Invertebr Pathol 79:179-191

Submitted: February 5, 2002; Accepted: July 3, 2002

Proofs received from author(s): September 20, 2002 